\title{
Summary of the XXIII ICPIG
}

\author{
A. Bouchoule, H. Brunet* and L.C. Pitchford* \\ GREMI, Université d'Orléans, UMR 6606 du CNRS, 45067 Orléans, France \\ * CPAT, Université Paul Sabatier, ESA 5002 du CNRS, 118 route de Narbonne, 31062 Toulouse, France
}

\section{INTRODUCTION}

The International Conference on Phenomena in Ionized Gases (ICPIG) is a biannual conference which covers most aspects of phenomena in ionized gases, with emphasis on low to moderate temperature plasmas. The tremendous growth in applications of low and moderate temperature plasmas (surface treatment, pollution control, microelectronics fabrication, and many others) makes this field dynamic, interdisciplinary, and rapidly evolving. The ICPIG series provides an international forum for presentation and discussion of fundamental physics of ionized gases and applied research underlying the newer as well as the more mature plasma-based technologies. There is no other international conference which covers the range of topics of the ICPIG.

Until 1995 the ICPIG venue traditionally alternated between sites in Eastern and Western Europe. The 1995 ICPIG at Stevens Institute in Hoboken, New Jersey, marked the first time the conference was held outside Europe, and this served the very useful purpose of making the conference truly international.

We, in France, were happy to have the chance to welcome the ICPIG back to Europe for the 1997 meeting, the twenty-third in the series. The XXIII ICPIG was held on the downtown campus of the University of Toulouse, from Thursday, July 17, to Tuesday, July 22, 1997. This campus is located in the historic center of Toulouse, and the central location proved to be especially attractive to participants and their accompanying persons. Every effort was made to keep the cost low so that participants who could not attend the meeting in the USA for financial reasons were able to be present in Toulouse. The attractive location and the low cost were key factors in the large participation at the meeting.

The local organization was assured by members of two laboratories from the University of Toulouse, the Centre de Physique des Plasmas et Applications de Toulouse (CPAT) and the Laboratoire de Genie Electrique de Toulouse (LGET). Continuity from meeting to meeting and guidance are provided by the ICPIG International Scientific Committee (ISC) which meets annually. The members of the ISC and of the Local Organizing Committee (LOC) are listed in the front of this special issue.

\section{PARTICIPATION}

The attendance at the XXIII ICPIG was larger than for the several previous meetings. A total of 561 participants took part in this meeting. The number of participants from each of the 36 countries represented at the ICPIG is shown in Table 1. 


\begin{tabular}{|l|c|l|c|}
\hline \multicolumn{1}{|c|}{ Country } & $\begin{array}{c}\text { number of } \\
\text { participants }\end{array}$ & Country & $\begin{array}{c}\text { number of } \\
\text { participants }\end{array}$ \\
\hline Algeria & 3 & Mexico & 2 \\
Australia & 6 & Netherlands & 10 \\
Austria & 2 & Norway & 5 \\
Belarus & 1 & Poland & 4 \\
Belgium & 4 & Portugal & 11 \\
Brazil & 1 & Republic of Moldova & 1 \\
Bulgaria & 3 & Romania & 8 \\
Canada & 6 & Russian Federation & 60 \\
Chili & 1 & Slovakia & 8 \\
Czech Republic & 32 & Slovenia & 1 \\
Egypt & 4 & Spain & 5 \\
Estonia & 2 & Switzerland & 1 \\
France & 183 & Turkey & 1 \\
Germany & 53 & UK & 16 \\
Iran & 1 & Ukraine & 5 \\
Ireland & 3 & USA & 31 \\
Israel & 7 & Yugoslavia & 6 \\
Italy & 16 & & 561 \\
Japan & 58 & TOTAL & \\
\hline
\end{tabular}

Table 1. Geographical distribution of participants at the XXIII ICPIG

One of the goals of the organization was to encourage student participation. To this end, low cost rooms were available for participants and the registration fee was reduced for students. These two factors were contributed to the large student participation.(138 students were present). The generous support of the sponsors and contributors of the XXIII ICPIG enabled the Local Organizing Committee to support in full or in part a number of participants from Eastern European countries.

\section{TECHNICAL PROGRAM}

The technical sessions of the XXIII ICPIG consisted of invited talks and poster presentations. The invited talks were given in either plenary sessions (for general lectures of broad interest) or in parallel sessions (for more specialized topics). The invited speakers were selected by the ISC. There were 31 invited speakers at the 1997 meeting, including 7 plenary lectures and 24 topical lectures. The international character of the ICPIG was reflected in the participation of 17 countries in the invited talks. The articles in this special issue include the texts of the invited talks at the XXIII ICPIG.

There were 513 contributed papers presented in the form of posters at the meeting. The poster sessions were arranged not to overlap with the presentation of the invited talks in order to give participants ample opportunity to meet and discuss with the presenters of the posters. The contributed papers themselves are short, a maximum of two pages in length, and these were printed and distributed to participants at the meeting. These ICPIG proceedings are organized in 5 volumes, one for each meeting day and a fifth one for 'late papers'. A requirement for inclusion of the papers in conference proceedings is that at least one of the authors be registered. The 'late papers' are those for which the authors registered after the deadline for printing the first 4 volumes. Additional copies of the proceedings are available and can be ordered from the LOC. Contributed papers from the proceedings of the XXIII ICPIG will appear in the INSPEC data base. 
A short overview on the contents of these contributions is given in table 2 which summarizes the list of subjects covered at the conference, as updated in 1996 by the ISC, and the number of contributions in each. At their meeting in 1996, the ISC decided to feature two subjects for special emphasis in 1997, (a) highly ionized, low pressure plasmas, and (b) high pressure, non-thermal plasmas.

\begin{tabular}{|l|c|}
\hline \multicolumn{1}{|c|}{ TOPIC } & $\begin{array}{c}\text { number of } \\
\text { posters }\end{array}$ \\
\hline Kinetics, thermodynamics and transport phenomena & 30 \\
Elementary processes & 27 \\
Low pressure glows & 42 \\
Coronas, sparks, surface discharges and high pressure glows & 35 \\
Arcs & 42 \\
High frequency discharges & 36 \\
Ionospheric, magnetospheric, and astrophysical plasmas & 7 \\
Plasma diagnostic methods & 50 \\
Plasma wall interactions, electrode and surface effects & 20 \\
Physical aspects of plasma chemistry, plasma processing of & 40 \\
surfaces, plasma wall interaction and thin film technology & \\
Generation and dynamics of plasma flows & 6 \\
Non-ideal plasmas. Clusters and dụsty plasmas & 17 \\
Waves and instabilities, including shock waves & 22 \\
Non-linear phenomena and self-organizing processes & 22 \\
Particle and laser beam interaction with plasmas & 6 \\
Plasma sources of radiation & 29 \\
Numerical modeling & 41 \\
Plasmas for environmental issues & 15 \\
Special topics emphasized at the 1997 meeting: & 16 \\
Highly ionized, low pressure plasmas & 10 \\
\hline High pressure, non-thermal plasma & 513 \\
\hline TOTAL & \\
\hline
\end{tabular}

Table 2. Number of contributed papers in each of the subject areas covered by the XXIII ICPIG

The poster sessions were very well attended in spite of the warm weather, and there were numerous animated discussions in the poster session area and in the gardens just outside where the coffee breaks and lunches were held.

A total of 661 contributed papers were submitted to and reviewed by the Local Organizing Committee. About $5 \%$ were rejected, mostly on the grounds that they were outside the subject area of the conference. A large number of papers, mostly from Eastern European countries, were accepted by the LOC, but the authors were unable to attend the meeting and present their papers. These papers were therefore not printed in the proceedings.

\section{PENNING PRIZE AND POSTER PRIZES}

The Penning Prize is awarded every two years, at the occasion of ICPIG, to an individual for work in the field of physics and technology of plasmas and ionized gases. The 1997 Penning prize, again sponsored by Philips Lighting, was awarded to Professor S. Takeda from Japan. The citation for the 1997 Penning 
Prize to Professor Takeda reads "for his many, long-standing contributions to the field of plasmas and ionized gases, and in particular, for his work on an extension of Paschen's law to high-frequency discharges and waves in plasmas". Professor Takeda accepted the Penning Prize. consisting of $\$ 1000$ and a certificate, and presented a lecture on gas discharge work in Japan. He also received a gold medal from the city of Toulouse in recognition of his having been awarded the Penning Prize. Professor Takeda was selected by the ISC from the 12 nominations which were submitted by members of the scientific community.

For the first time the ICPIG Conference distinguished two contributed papers with awards, one for theory/modeling and the other for experimental work. The 1997 ICPIG poster prize winners were E. Robert, C. Cachoncinlle, A. Khacef, R. Viladrosa and J.M. Pouvesle from GREMI, CNRS/Université d'Orléans, France for experimental work and A. Bogaerts and R. Gijbels from University of Antwerp, Belgium for theory/modeling.

\section{WORKSHOPS}

An industrial workshop has traditionally been organized to coincide with the ICPIG. This year the industrial workshop, open to all registered participants of the ICPIG, was held in the middle of the conference on Saturday afternoon. Six leaders in research and development in large companies accepted invitations to speak, and attendance at the workshop was very good. The following topics were presented :

Plasma Processing of Semiconductors (J.N. Bardsley, LLNL, USA)

Plasma Display Panels (H. Doyeux, Thomson Tube Electronics, France)

Plasma Addressed Liquid Crystal Displays (K. Ilcisin, Technical Visions, USA) .

Electromagnetic Propulsion (A. Cadiou, CNES, France)

Circuit Breakers and Switches (M. Barrault, Schneider, France)

Waste Treatment with Thermal Plasmas (M. Labrot, Aérospatiale, France).

The organizers wish to express again their appreciation to these speakers for their participation in the workshop.

Another special industrial workshop on plasma technologies for environmental issues was organized the day before the conference. More than 50 specialists, mainly from Europe and USA, attended this special workshop. This workshop was organized by the Center of Technological Ressources (CRT) in Plasmas and Lasers which was recently established in France. Reports will be available though the CRT (B. Bergaya, CRT Plasma-Laser, UFR Sciences, 45067 Orléans, France ).

\section{SOCIAL EVENTS}

Very important parts of any conference are the social events, and we were happy to have this opportunity to share some of the pleasures of life in southern France with the attendees at the XXIII ICPIG. A welcome reception was held outside in the garden of the campus on Wednesday evening, July 16 . For the accompanying persons, there was a 2-hour walking tour of Toulouse on Thursday afternoon and bus trips on Friday and Monday to Albi and Cordes and to Carcasonne which were 'sold-out'. The conference banquet was held in the Hotel Dieu, a Toulouse landmark on the banks of the Garonne River in the center of city. The after-dinner talk was a hilarious tale of the "baguette laser " given by Dr. Jean-Michel Pouvesle (who, incidentally, was one of the poster prize winners!). A conference excursion to the countryside around Toulouse was organized on Sunday, and there were about 240 people who made this excursion. On Monday evening, the mayor of Toulouse hosted a reception for all ICPIG participants in the magnificent 'Salle des Illustres' in the Toulouse City Hall. At this event, medals from the city of Toulouse were presented to the Professor Takeda and the poster prize winners. 


\section{SPONSORS AND CONTRIBUTORS}

The success of this conference is due in part to the generous support of our sponsors. It is thanks to this support that the cost for participants was a minimum thereby allowing more people to attend. We gratefully acknowledge the sponsors of XXIII ICPIG, the list of which appears in the front of this volume.

\section{XXIV ICPIG}

The 24th ICPIG will be held in Warsaw in July 1999. We hope to see you all again there ! 